\title{
Structural changes in the pulmonary arteries and veins in tetralogy of Fallot
}

\author{
Alison Hislop and Lynne Reid \\ From the Department of Experimental Pathology, Cardiothoracic Institute, Brompton Hospital, London
}

The pulmonary arteries or veins from 6 children with tetralogy of Fallot have been injected with a barium sulphate and gelatin mixture. The branching pattern of the airways, arteries, and veins was normal. At all ages quantitative studies showed a decrease in total lung volume and in both pulmonary artery and vein size. In the intra-acinar region small arteries and veins were increased in number but the alveolar number was decreased. The pulmonary arteries were relatively more muscular than normal as shown both by increased medial wall thickness and by extension of muscle into smaller vessels than is normal.

The altered haemodynamic conditions in congenital heart disease affect the pulmonary vessels. In tetralogy of Fallot pulmonary artery blood flow is reduced (Dollery et al., 196I) and pressure within the pulmonary artery is low. In many cases flow is increased at capillary level due to collateral circulation (Bing, Vandam, and Gray, 1947). Pathological studies have indicated the presence of thrombi and bronchial collateral circulation (Rich, 1948; Dammann and Ferencz, 1956). Measurements of arterial wall thickness, made in uninjected material, have given conflicting results. Some workers report a normal wall thickness (Dammann and Ferencz, 1956; Granston, 1958), others a reduction (Best and Heath, 1958; Wagenvoort and Edwards, 1961). Naeye (196I) from planimetric studies reported that even before birth there was a reduction in area of the arterial media.

Received 2 March 1973.
The normal development of the pulmonary arteries and veins during foetal life and childhood has recently been described using precise quantitative methods (Hislop and Reid, 1972, 1973a, and b). These studies provide an accurate basis for investigation of diseased lungs. This paper describes the results of quantitative analysis on 6 cases of tetralogy of Fallot, in 5 of whom the pulmonary arteries were injected and in one the pulmonary veins.

\section{Subjects and methods}

Lungs from six patients, who died either at operation or in the postoperative period and were aged $1 \frac{1}{12}, 3 \frac{3}{4}, 4 \frac{1}{4}, 4 \frac{1}{2}, 6$, and 8 years, were studied. The relevant clinical features are summarized in Table $I$, the cases being designated by age at death. All cases had a reduced pulmonary blood

TABLE I Clinical features of cases with tetralogy of Fallot

\begin{tabular}{|c|c|c|c|c|c|c|}
\hline $\begin{array}{l}\text { Case } \\
\text { No. }\end{array}$ & $\begin{array}{l}\text { Age } \\
\text { (yr) }\end{array}$ & $\begin{array}{l}\text { Artery size } \\
\text { seen on } \mathrm{x} \text {-ray }\end{array}$ & $\begin{array}{l}\text { Pulmonary } \\
\text { artery pressure } \\
(\mathrm{mm} H \mathrm{~g})\end{array}$ & $\begin{array}{l}\text { Pulmonary/ } \\
\text { systemic } \\
\text { flow }\end{array}$ & $\begin{array}{l}\text { Pulmonary } \\
\text { flow } \\
\text { (l./min) }\end{array}$ & $\begin{array}{l}\text { Systemic } \\
\text { saturation (\%) }\end{array}$ \\
\hline I & $I \frac{1}{12}$ & $\downarrow$ & - & $0.7: 1$ & $2 \cdot 0$ & 82 \\
\hline 2 & $3 \frac{3}{4} \star$ & $\downarrow$ & - & $0.6: 1$ & - & $8 I$ \\
\hline 3 & $4 \frac{1}{4}$ & $\downarrow$ & - & $0.3: 1$ & $I \cdot 7$ & 64 \\
\hline 4 & 6 & $\downarrow$ & - & $0.6: 1$ & $3 \cdot 1$ & 85 \\
\hline 5 & $8 \star$ & $(\downarrow)$ & I $7 / I I$ & I : I & $5 \cdot 8$ & 97 \\
\hline 6 & $4 \frac{1}{2}$ & $\downarrow$ & $12 / 5$ & $0.2: 1$ & $I \cdot 8$ & 54 \\
\hline
\end{tabular}

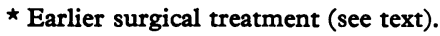
$\downarrow$ reduced.

( ) only slight change.
} 
flow and polycythaemia and in the cases in which a pulmonary artery pressure had been recorded this was also reduced. In all a diagnosis of tetralogy of Fallot was confirmed at necropsy.

Cases 2 and 5 had been treated surgically previously. In Case 2 a palliative operation to relieve the obstruction to the right outflow tract led to slight clinical improvement. Case 5 had improved clinically after a Blalock anastomosis, which had been carried out 3 years before death. Catheterization and angiography 6 months before death showed that the Blalock anastomosis was still patent. The child died shortly after pulmonary valvotomy and infundibular resection.

The arteries or veins were injected by the usual departmental method with a mixture of barium sulphate and gelatin at $60^{\circ} \mathrm{C}$ and pressure of $100 \mathrm{~cm} \mathrm{H} \mathrm{H}_{2} \mathrm{O}$. Filling reaches to vessels $15 \mu \mathrm{m}$ in diameter but does not penetrate capillaries. All vessels on the arterial side of the capillary bed are described as arteries and designated by structure, and on the venous side as veins. The words 'arteriole' and 'venule' have been avoided since these terms have led to confusion because they were defined in various ways. Quantitative studies included measurements of arteriograms and venograms, serial reconstruction of branching pattern, estimation of percentage wall thickness and of muscle extension along veins and arteries, the size of arteries accompanying airways (Davies and Reid, 1970; Hislop and Reid, I970), and also the number of arteries, veins, and alveoli in a unit area of lung tissue (Hislop, I97I).

\section{Results}

All lungs were reduced in volume for age, to a greater amount in the older cases.

\section{Branching pattern}

Arteriograms (Fig. I) showed a normal branching pattern of the main arterial pathways but an increased density of background haze of small vessels. In Cases I and 3 filled bronchial vessels could be discerned on the arteriogram. Measurement of the main pulmonary artery pathways showed them to be reduced in diameter for age (Fig. 2). The decrease in diameter was greater at the hilum than the periphery and the difference increased with age. The gradient from hilum to periphery was reduced in all

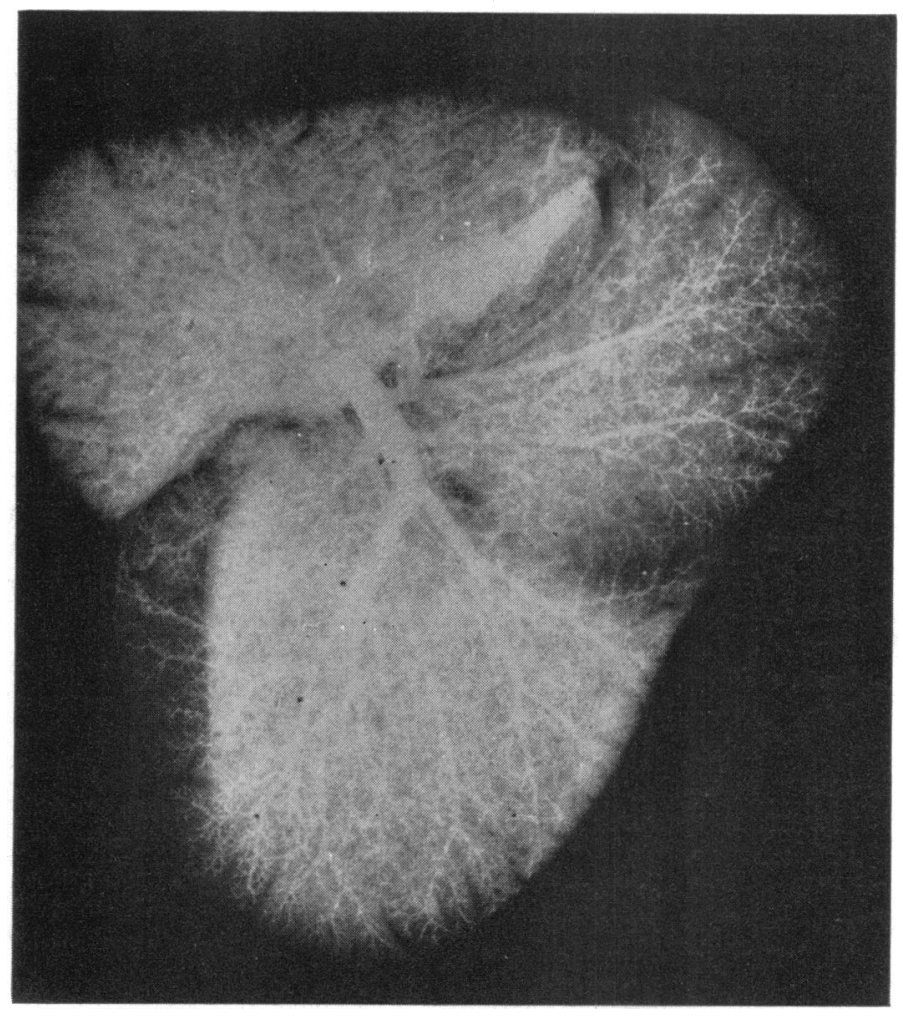

FIG. I Arteriogram of the right lung of Case 5 after arterial injection with a barium sulphate and gelatin suspension. The main arterial pathways are decreased in size for age and the background haze is abnormally dense. 
cases. The one venogram (Case 6) showed similar changes in veins to those in the arteries.

Dissection and serial reconstruction in Cases 4, 5 , and 6 confirmed that the pre- and intra-acinar arterial, venous, and airway branching pattern was normal, though the size of the vessels was much reduced.

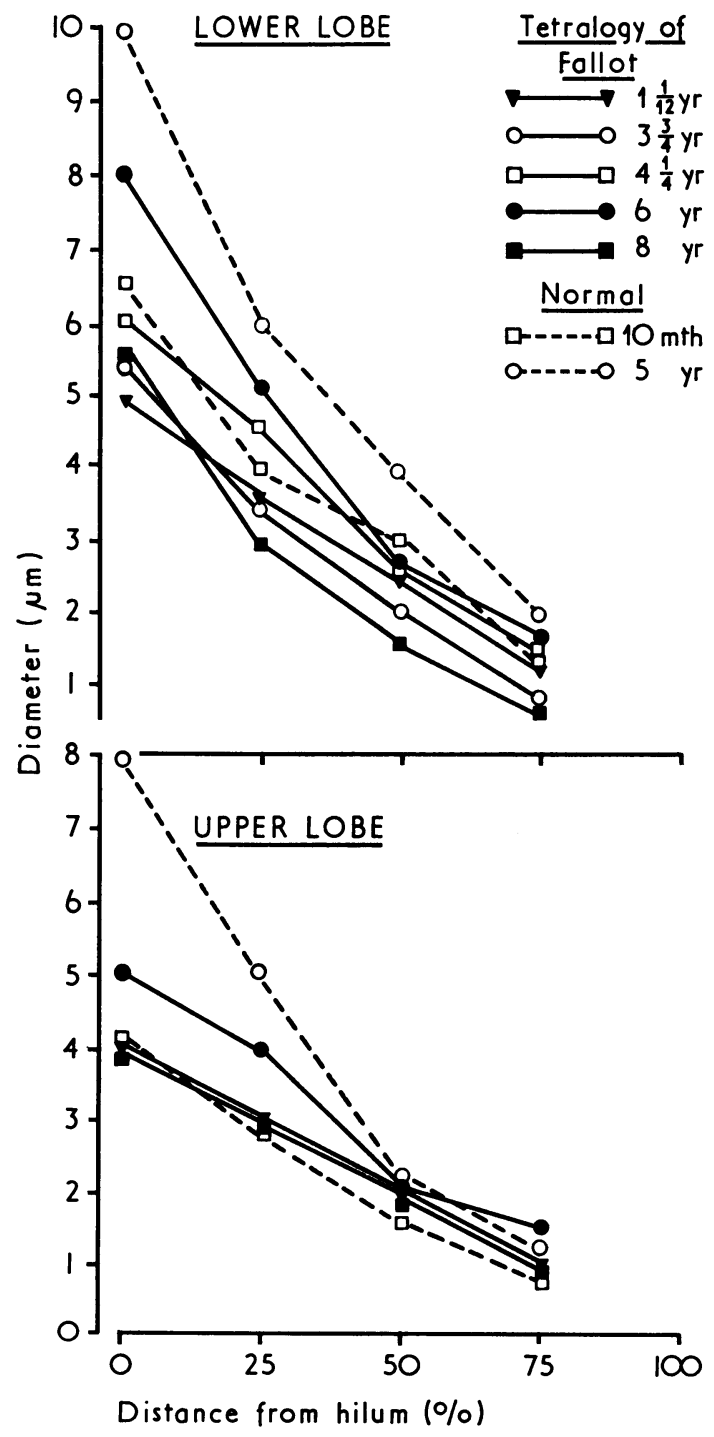

FIG. 2 Measurements on arteriograms of the diameter of the main arterial pathway to the upper and lower lobe in 5 cases of tetralogy of Fallot and 2 normal lungs. The former all show a reduction in diameter.
Vessels and alveoli per unit area of lung

In all cases the total number of alveoli per square centimetre of lung section was reduced by comparison with normal lungs of similar age (Table 2). The alveoli were thus larger than normal - a slight degree of emphysema. Since the total lung volume was also reduced there probably was a reduced total number of alveoli.

TABLE 2 Number of arteries and alveoli in one square centimetre of lung tissue and the ratio of alveoli to arteries

\begin{tabular}{|c|c|c|c|c|}
\hline $\begin{array}{l}\text { Case } \\
\text { No. }\end{array}$ & $\begin{array}{l}\text { Age } \\
(y r)\end{array}$ & Alveoli $/ \mathrm{cm}^{2}$ & Arteries $/ \mathrm{cm}^{2}$ & $\begin{array}{l}\text { Ratio alveoli } \\
\text { arteries }\end{array}$ \\
\hline $\mathbf{I}$ & $I \frac{1}{12}$ & 10,541 & 336 & $31 \cdot 37$ \\
\hline 2 & $3 \frac{3}{4} \star$ & 7,462 & 231 & 19.95 \\
\hline 3 & 44 & 8,644 & 374 & $23 \cdot 11$ \\
\hline 4 & 6 & 7,251 & 347 & $20 \cdot 89$ \\
\hline 5 & $8^{\star}$ & 7,313 & 330 & $22 \cdot 16$ \\
\hline \multicolumn{5}{|c|}{ Normal } \\
\hline \multicolumn{2}{|c|}{ Io mth } & 12,418 & 287 & $43 \cdot 26$ \\
\hline \multicolumn{2}{|c|}{$4 \mathrm{yr}$} & 9,529 & 233 & $40 \cdot 8$ \\
\hline \multicolumn{2}{|l|}{$5 \mathrm{yr}$} & 9,123 & 195 & $46 \cdot 8$ \\
\hline \multicolumn{2}{|l|}{ IO yr } & 8,580 & 179 & $47 \cdot 9$ \\
\hline
\end{tabular}

^ Earlier surgical treatment (see text).

The number of arteries, less than $200 \mu \mathrm{m}$ external diameter in a square centimetre, was counted. These vessels are in the alveolar region and available for gas transfer, but those less than $160 \mu \mathrm{m}$ in lumen diameter are not seen as separate lines on the arteriogram (Millard, 1965). The number was increased in all but Case 2, the increase being most pronounced in vessels less than $75 \mu \mathrm{m}$ external diameter. When related to the reduced alveolar number there is a relative increase in arteries in all cases (Table 2).

In the one case where the veins had been injected, the concentration of veins per unit area of lung was similar to the normal but when related to alveolar number was increased, particularly those veins below $75 \mu \mathrm{m}$. It is unlikely that this increase in small vessels represented an increase in bronchial collateral ones, since there was little increase in bronchial artery size, and cross filling was only seen in the central part of the lung not at the periphery.

\section{Structure of vessels}

The structural changes in the arteries in 5 cases are summarized in Table 3 . In all 5 cases, in vessels 
TABLE 3 Summary of structural changes in arteries in cases with tetralogy of Fallot

\begin{tabular}{|c|c|c|c|c|c|}
\hline \multirow[b]{2}{*}{$\begin{array}{l}\text { Arteriograms } \\
\text { Pattern } \\
\text { Lumen diameter }\end{array}$} & \multicolumn{4}{|c|}{ Case No. and age (yr) } & \multirow[b]{2}{*}{$\begin{array}{l}5,8^{\star} \\
\downarrow\end{array}$} \\
\hline & $\begin{array}{l}I, I \frac{1}{12} \\
N^{\downarrow} \\
\downarrow\end{array}$ & $\begin{array}{l}2,3 \frac{3 \pi}{4} \\
\downarrow\end{array}$ & $\begin{array}{l}\stackrel{3,4 \frac{1}{N}}{\downarrow} \\
\downarrow\end{array}$ & $\begin{array}{l}4,6 \\
\downarrow\end{array}$ & \\
\hline \multicolumn{6}{|l|}{ Wall structure } \\
\hline $\begin{array}{l}\text { \% wall thickness } \\
\text { Muscle extension into small vessels } \\
\text { Muscle extension into acinus } \\
\text { Diameter of arteries with airways } \\
\text { Structure of arteries with airways } \\
\text { Right ventricular muscle }\end{array}$ & $\begin{array}{l}\uparrow \\
\mathbf{N} \\
\downarrow \\
\downarrow \\
\downarrow \\
\uparrow\end{array}$ & $\begin{array}{l}\uparrow \uparrow \\
\uparrow \\
\mathbf{N} \\
\downarrow \\
\mathbf{N} \\
\uparrow\end{array}$ & $\begin{array}{l}(\uparrow) \\
\mathbf{N} \\
\downarrow \\
\downarrow \\
\downarrow \\
\uparrow\end{array}$ & $\begin{array}{l}\uparrow \\
\uparrow \\
\mathbf{N} \\
\downarrow \\
\mathbf{N} \\
\uparrow\end{array}$ & $\begin{array}{l}\uparrow \uparrow \\
\uparrow \\
(\uparrow) \\
\downarrow \\
\mathbf{N} \\
\uparrow\end{array}$ \\
\hline $\begin{array}{l}\mathbf{N}=\text { Normal. } \\
\uparrow=\text { Increase in size or muscle. } \\
\downarrow=\text { Decrease in size or muscle. } \\
(\text { ) = Only slight change. } \\
\star \text { Earlier surgical treatment (see text). }\end{array}$ & & & & & \\
\hline
\end{tabular}

greater than $200 \mu \mathrm{m}$ external diameter the thickness of the muscle coat was higher than normal for the same age, particularly in the 2 cases where surgical attempt had been made to increase the flow. Though increased, the wall thickness was less than is normal at birth so there had been some normal postnatal regression. All cases, in vessels below $200 \mu \mathrm{m}$, showed the normal relative increase in percentage wall thickness, but, when compared with normal children, these vessels were not abnormally thick, except in Case 5 (Hislop and Reid, r973a).

Wall thickness measured both in injected and uninjected veins was normal.

Population counting of the small arteries showed that in Cases 2, 4, and 5 there was an abnormal extension of muscle into smaller vessels (Cases 2 and 5 had surgical treatment). In Cases I and 3 the distribution of muscle in small vessels was normal.

Measurements were made of the diameter and structure of arteries accompanying terminal and respiratory bronchioli, alveolar ducts, and alveoli. In each case at all levels the arteries were substantially smaller in diameter than normal. In Cases 2 and 4 muscle distribution in the vessels within the acinus was normal; in Cases $I$ and 3 a reduction was found in the number and extension of muscular arteries and in Case 5 a slight increase in muscle extension. The differences, shown in Fig. 3, are not great and could lie within the limits of individual variation.

In the 2 cases that had been treated surgically the changes were similar throughout the lung examined. In Case 2 there was some intimal thicken-

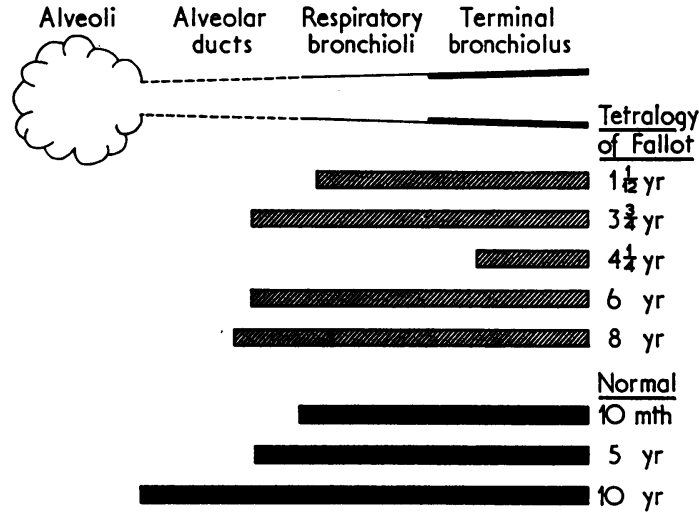

FIG. 3 Diagram illustrating the extension of muscle in the walls of small arteries within the acinus, for 5 cases of tetralogy of Fallot and 3 normal lungs.

ing in medium-sized arteries and in Case 5 considerable intimal thickening in both arteries and veins and some thrombotic lesions. There was no evidence of thrombosis or intimal thickening in the other 4 cases.

\section{Discussion}

The precise quantitative methods used in this study have established the presence of new structural features in the pulmonary circulation in tetralogy of Fallot. 


\section{Structural changes}

In this group of 6 cases of tetralogy of Fallot the age range was 13 months to 8 years. Despite this, the pathological changes in the pulmonary circulation were similar in all, in contrast to lungs from infants with ventricular septal defect where structural changes vary widely from cáse to case (Hislop, 197I).

The lungs in all cases were reduced in volume, and the blood vessels, both arteries and veins, were reduced in size probably to a greater degree than was lung volume. The degree of hypoplasia increased with age even after operation.

Though the vessels were small, the branching pattern of arteries and veins, both pre- and intraacinar, was normal. Normally the pre-acinar arterial branching is complete by the I6th week of gestation (Hislop and Reid, 1972), intra-acinar branching occurring during later foetal life and childhood (Hislop and Reid, 1973a). In the lung, development of the circulation is under strong genetic control, since before birth flow is so small that growth is not in response to functional demand. Reduced flow in these cases not only had not prevented multiplication of arteries during foetal life or childhood but vessels beyond the alveolar ducts were increased in number, particularly arteries. This was demonstrated by the dense background haze and the number of arteries within a unit area of lung. The intra-acinar region has responded to the reduced flow by excessive multiplication.

The increase in the small arteries that are precapillary in position may lead to a larger area for blood-gas exchange and will tend to reduce the rate of flow; both these factors may increase the chance of oxygenation within the lung. A perplexing fact is that though the intra-acinar arteries are increased the post-acinar venous system is still hypoplastic. Perhaps flow is the important factor for vein size.

In all the cases of tetralogy of Fallot the arterial wall thickness was increased. This was not the expected result since previous authors have reported a normal or low wall thickness (Dammann and Ferencz, 1956; Naeye, 196I) which they believed to be related to the low flow (Nadas, 1963). The greatest increase in muscle was in those cases where an attempted correction had been made, and the resultant higher pressure and flow may explain the further increase in these two cases, though in only one (Case 5) were the haemodynamic conditions restored to near normal. Ferencz (1960) and Daoud, Kaplan, and Helmsworth (1966) have demonstrated an increase in wall thickness after surgical correction but only in cases where the flow became greater than normal. In all our cases the increased wall thickness still represented a drop in wall thickness since birth, suggesting either an arrest in loss of muscle or a secondary increase, the latter almost certainly in the corrected cases

Though the arteries in these cases are more muscular than normal when judged by size, either by wall thickness or extension of muscle into small vessels, muscle does not extend further to the periphery of the acinus than normal, i.e. the normal non-muscular arterial pattern characteristic of childhood (Hislop and Reid, 1973a) is found within the acinus. The extension is not seen because the vessels within the acinus are small. The extension of muscle into small arteries may be to maintain the normal muscular distribution within the acinus.

The pulmonary veins show the same pattern of change as the arteries. We have shown a reduction in vein size, whereas Wagenvoort (1970) considered the veins to be dilated. In the present study though it has also been possible to demonstrate an increase in number of small veins in the acinar region, venous structure seemed normal.

The pre-acinar arteries and veins seem to have responded to the abnormal haemodynamic situation by changes in size and structure, as have the intra-acinar arteries and veins which have also increased in number.

\section{Clinical considerations}

In Cases 2 and 5 palliative surgery had been carried out; in the former the clinical changes were small, but in the latter considerable improvement had occurred. The increase in flow known to have been produced in Case 5 had not led to any lessening of vessel hypoplasia and had probably been detrimental in that greater muscle hypertrophy and intimal thickening with thrombosis were also present. In Case 2 with less increase in flow there was less muscle hypertrophy but still signs of intimal thickening. In these cases the intimal and thrombotic changes seem to be the result of increased flow rather than of decreased, as previously reported (Rich, 1948). All in this series had polycythaemia.

The general metabolic rate of children with tetralogy of Fallot is below normal (Bing et al., 1947), and the children are usually small for age. This was so in the present series and in addition the lungs were abnormally small for the size of the child. On the chest radiograph, measurements of lung length and width were made and compared with the normal centiles of radiographic growth that have recently been prepared for children of 6 years and over (Simon et al., 1972). In both features the two cases over 6 years were close to the 3rd centile. By extrapolating the normal centiles it seems that 
the younger cases were also at this level. These children were also close to the 3 rd centile for height. In the normal the lung surface area has a linear relation to the body surface area (Dunnill, 1962). The emphysematous alveoli decrease surface area even further. Reduced blood flow increases distensibility and in these cases this may have contributed to the emphysema.

We are grateful to Dr. M. Joseph, Dr. R. Gibson, Mr. M. Paneth, Mr. W. P. Cleland, and Dr. K. F. W. Hinson of the Brompton Hospital, and to Dr. A. G. Leatham and Mr. C. Drew of St. George's Hospital for allowing us to study these specimens. Dr. G. Simon has helped with interpretation of the radiographs and angiograms and Dr. S. Godfrey with the catheter studies.

This study was supported by the Research Committee of the Board of Governors of the Brompton Hospital and is part of the work accepted for the degree of Ph.D. London University. Dr. Hislop is currently supported by the British Heart Foundation.

\section{References}

Best, P. V., and Heath, D. (1958). Pulmonary thrombosis in cyanotic congenital heart disease without pulmonary hypertension. Fournal of Pathology and Bacteriology, 75, 281 .

Bing, R. J., Vandam, L. D., and Gray, F. D. (1947). Physiological studies in congenital heart disease. II. Results of pre-operative studies in patients with tetralogy of Fallot. Bulletin of the fohns Hopkins Hospital, 80, 121 .

Dammann, J. F., and Ferencz, C. (1956). The significance of the pulmonary vascular bed in congenital heart disease. I. Normal lungs. II. Malformations of the heart in which there is pulmonary stenosis. American Heart fournal, 52, 7.

Daoud, G., Kaplan, S., and Helmsworth, J. A. (1966). Tetralogy of Fallot and pulmonary hypertension. Complication after systemic-to-pulmonary anastomosis. American Fournal of Diseases of Children, III, 166.

Davies, G., and Reid, L. (1970). Growth of the alveoli and pulmonary arteries in childhood. Thorax, 25, 669.

Dollery, C. T., West, J. B., Wilcken, D. E. L., and HughJones, P. (I96I). A comparison of the pulmonary blood flow between left and right lungs on normal subjects and patients with congenital heart disease. Circulation, 24, 617.

Dunnill, M. S., (1962). Postnatal growth of the lung. Thorax, 17, 329.
Ferencz, C. (1960). The pulmonary vascular bed in tetralogy of Fallot. II. Changes following a systemic - pulmonary arterial anastomosis. Bulletin of the fohns Hopkins Hospital, 106, 100.

Granston, A. S. (1958). Morphologic alterations of the pulmonary arteries in congenital heart disease. Proceedings of the Institute of Medicine of Chicago, 22, 116.

Hislop, A. (197I). The fetal and childhood development of the pulmonary circulation and its disturbance in certain types of congenital heart disease. Ph.D. Thesis, University of London.

Hislop, A., and Reid, L. (1970). New pathological findings in emphysema of childhood: I. Polyalveolar lobe with emphysema. Thorax, $25,682$.

Hislop, A., and Reid, L. (1972). Intra-pulmonary arterial development during fetal life - branching pattern and structure. Fournal of Anatomy, 113,35 .

Hislop, A., and Reid, L. (1973a). Pulmonary arterial development during childhood: branching pattern and structure. Thorax, 28, 129.

Hislop, A., and Reid, L. (1973b). Fetal and childhood development of the intrapulmonary veins in man - branching pattern and structure. Thorax, 28, 313.

Millard, F. J. C. (1965). The development and the electrocardiographic diagnosis of right ventricular hypertrophy in chronic lung disease. M.D. Thesis, University of London.

Nadas, A. S. (1963). Paediatric Cardiology, 2nd ed. Saunders, Philadelphia.

Naeye, R. L. (196I). Perinatal changes in the pulmonary vascular bed with stenosis and atresia of the pulmonic valve. American Heart fournal, 61, 586.

Rich, A. R. (1948). A hitherto unrecognized tendency to the development of widespread pulmonary vascular obstruction in patients with congenital pulmonary stenosis (tetralogy of Fallot). Bulletin of the fohns Hopkins Hospital, 82, 389.

Simon, G., Reid, L., Tanner, J. M., Goldstein, H., and Benjamin, B. (1972). Growth of radiologically determined heart diameter, lung width, and lung length from 5-19 years, with standards for clinical use. Archives of Disease in Childhood, 47, 373.

Wagenvoort, C. A. (1970). Morphologic changes in intrapulmonary veins. Human Pathology, 1, 205.

Wagenvoort, C. A., and Edwards, J. E. (I96I). The pulmonary arterial tree in pulmonic atresia. Archives of Pathology, 7r, 646.

Requests for reprints to Professor Lynne Reid, Department of Experimental Pathology, Cardiothoracic Institute, Brompton Hospital, London $\mathrm{SW}_{3} 6 \mathrm{HP}$. 